Synthesis, part of a Special Feature on Exploring Opportunities for Advancing Collaborative Adaptive Management (CAM): Integrating Experience and Practice

\title{
Designing Collaborative Processes for Adaptive Management: Four Structures for Multistakeholder Collaboration
}

\author{
$\underline{\text { Jennifer D. Pratt Miles }}^{1}$
}

ABSTRACT. Parties should consider a collaborative approach to scientific inquiry and learning when there are multiple jurisdictions, resource users, and viewpoints about the best way to manage a social-ecological system. A collaborative process provides a forum for scientists, managers, and other stakeholders to raise and explain concerns, articulate management goals, and suggest strategies to address concerns and management actions to achieve goals. Collaborative problem solving engages parties in dialogue that facilitates understanding of different perspectives and creates an opportunity to reframe problems as hypotheses to be tested through the adaptive management process.

I review four potential structures for multistakeholder collaboration that have been used by medium- to large-scale adaptive management programs in the U.S., and identify factors to consider when determining if one of these structures would be appropriate for a particular situation. These mechanisms include: establishing a Federal Advisory Committee, forming a multistakeholder body convened by a nonfederal entity, creating a body through legislation or cooperative agreement, and seeking an exemption from the Federal Advisory Committee Act (FACA). When designing a collaborative process, parties should consider the degree of collaborative decision making desired, amount of resources that will be required, length of time necessary to design and establish the group, who will make decisions, and how decisions will be made.

Key Words: adaptive management; collaboration; collaborative process; ecosystem management; natural resource management; stakeholder

\section{INTRODUCTION}

A collaborative adaptive management process is one in which the principles of collaborative problem solving are integrated with the steps of the adaptive management cycle. Collaborative problem solving is a process that involves identifying stakeholder interests and seeking solutions that address multiple interests through a "creative process in which the participants discover the differences between them by listening to one another" (Gates et al. 1991:105). The Boulder Principles offer principles for effective collaboration, such as promoting participation by all affected parties; clearly articulating process goals and parameters; making all aspects of the process transparent, e.g., how decisions are made; seeking to understand different points of view and underlying interests; respecting different types of knowledge; making technical information available and accessible; and setting up mechanisms for implementing, monitoring, and updating agreements (Woodrow and Ghais 1998). The Center for Appropriate Dispute Resolution in Special Education identifies six steps in a collaborative process: share perspectives, define the issues, identify the interests, generate options, develop criteria for deciding among options, and evaluate options and reach agreement (Windle and Warren 2013).

Adaptive management is a systematic method for learning by doing (Walters 1997) that "treats actions and policies as experiments that yield learning. An adaptive approach mimics the scientific method: specifies hypotheses, highlights uncertainties, structures actions to expose hypotheses to field tests, processes and evaluates results, and adjusts subsequent actions in light of those results" (Stankey et al. 2003:41).

Nyberg set forth six overarching steps in the adaptive management process: assess, design, implement, monitor, evaluate, and adjust (Nyberg 1999). The combination of collaborative process and adaptive management is referred to as adaptive comanagement or collaborative adaptive management (Olsson et al. 2004a, b, Susskind et al. 2012). An adaptation of Nyberg's adaptive management cycle (Fig. 1) shows how these two paradigms can be integrated, and how each of the steps has become further defined through practice.

In complex social-ecological systems, a collaborative process can help identify knowledgeable, affected, and interested parties who should be involved in an adaptive management process. A collaborative process can also provide a forum for articulating different understandings of how the ecosystem works, evaluating the effectiveness of different management strategies, and making adjustments if management objectives are not met.

Based on experience designing collaborative processes for adaptive management programs in the U.S. and drawing from lessons learned through the Collaborative Adaptive 
Fig. 1. Annotated adaptive managment cycle, adapted from Nyberg 1999.

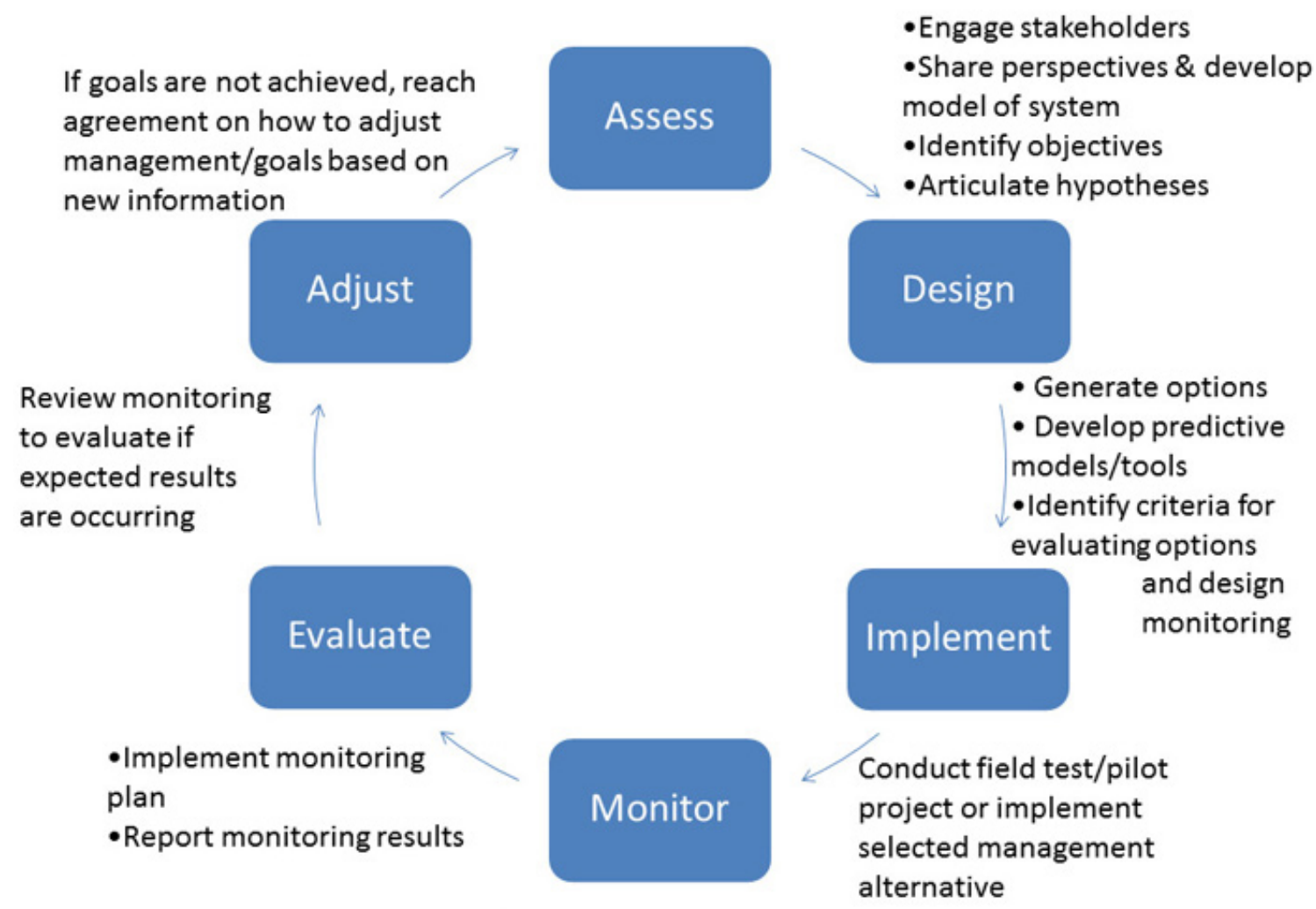

Management Network (CAMNet; http://www.adaptivemanagement. net/), I set forth principles for collaborative process in an adaptive management context, describe four structures that can be used for collaboration in an adaptive management process, and suggest factors to consider when selecting among these options or creating a new structure. Throughout the paper, examples from practice are used to illustrate observations and suggestions. In particular, examples are drawn from the Comprehensive Everglades Restoration Plan (CERP; http://www.evergladesplan.org/index.aspx), Glen Canyon Dam Adaptive Management Program (http://www. usbr.gov/uc/rm/amp/index.html), Las Cienegas National Conservation Area Resource Management Plan (U.S. Department of the Interior 2003 and http://www.blm.gov/az/ st/en/prog/blm_special_areas/ncarea/lascienegas.html), and the Platte River Recovery Implementation Program (Smith 2011 and http://www.platteriverprogram.org/Pages/default. aspx).

\section{PRINCIPLES FOR DESIGNING COLLABORATIVE PROCESS IN AN ADAPTIVE MANAGEMENT CONTEXT}

The following principles can help parties design collaborative processes to support adaptive management.
Provide forums for interaction between managers, scientists, and other stakeholders

In the seminal work on adaptive management, Adaptive Environmental Assessment and Management edited by C. S. Holling, foreword author Martin Holdgate observes that:

Because of uncertainties, environmental science can be used to guide the development and management of natural resources only if there is a continuing interaction between the scientist and the manager. Dialogue is needed at the outset to identify the key questions posed by a new development or management program. ...Such a preliminary dialogue guides field study, analysis, and modeling and the consequent judgment about the likely impact of new development or alternative possible management methods. (Holling 1978)

Because scientists and managers receive different training and focus on different tasks, a collaborative process can provide a framework for interaction between these two critical sets of players in the adaptive management process.

In complex systems, other stakeholders often bring expertise and knowledge that can contribute to an adaptive management 
process. For example, stakeholders can help identify questions and issues that are important to determining the efficacy of a management approach, develop creative approaches to addressing management challenges, conduct and assess monitoring, and help identify when a management strategy is or is not achieving its desired ends. As noted in the document summarizing key points from a meeting between an Independent Expert Review Panel and the Comprehensive Everglades Restoration Plan's science arm, REstoration, COordination, and VERification (RECOVER),

Panel members stressed that stakeholders must be engaged in the restoration process early and often, and that effective stakeholder engagement requires long-term investments in relationships with those who care about the resources being managed. Some panel members observed that while original thinking about adaptive management was focused on engaging scientists and managers, experience with large-scale adaptive management programs such as the Glen Canyon Dam and the Platte River has made clear that involvement of other interested parties is critical to success. Outreach programs must be funded and opportunities for two-way communication on AM issues must be created (B. Stinson and J. Pratt Miles 2010, CERP Adaptive Management Integration Guide: Expert Panel Meeting Highlights, unpublished manuscript).

Invite and document input from affected stakeholders at key junctures in the adaptive management process

Adaptive management provides a structured approach for framing competing objectives as testable hypotheses and learning from ecosystem response to management actions. A collaborative process provides the framework for involving and engaging multiple interest groups to articulate what the competing goals are; how they can be tested, monitored, and evaluated in a scientific and objective way; and how in some cases management approaches can be designed to achieve more than one goal. Collaboration should occur at each step of the adaptive management process, including development of models and identification of management goals in the assess step, articulation of alternative management options and definition of experiments in the design step, monitoring and evaluation of monitoring, and determining how to adjust management if goals are not being met. Issues, questions, agreements, and different points of view should be documented throughout the process. This can build understanding and trust among parties and provides a record of ground covered for those new to the process.

Resource users, academics, and others can contribute knowledge of ecological systems that improves the accuracy of conceptual and computer-based models. According to the U.S. Fish and Wildlife Service's web site for the North
American Adaptive Harvest Management program, the process for setting duck hunting regulations each year is informed by hunter questionnaires and other assessment tools that "provide information about harvest levels, population size, and habitat condition" (U.S. Fish and Wildlife Service Center 2012).

Collaborative approaches involve identification of multiple options to address agreed upon goals. In an adaptive management context, this approach can be used to identify a range of alternative management strategies to be tested. Stakeholders can help identify management questions or hypotheses to be addressed as well as alternative management strategies to be tested. In September 2007, the Save Our Bosque Task Force, a not-for-profit organization working on river restoration on the Middle Rio Grande, partnered with federal land managers, scientists, and volunteers to conduct a two-day workshop to graphically map the key components of the system and causal relationships among them. This conceptual model enabled the group to articulate hypotheses about what factors contributed to degradation of the ecosystem, and identify management actions to restore the system that could be tested through adaptive management (J. Pratt Miles 2007, Save Our Bosque Task Force Adaptive Management Workshop II, personal observation). At the Las Cienegas National Conservation Area (LCNCA), the Bureau of Land Management (BLM) is engaged in a collaborative process with permittees, conservation organizations, hiking groups, and other stakeholders to identify and test different treatment options for invasive species in the grassland. In this adaptive management process, the BLM and its partners are trying different chemical, mechanical, and prescribed fire treatments and monitoring their effectiveness (K. Simms and G. Bodner 2011, Presentation on Collaboration and Adaptive Management at Las Cienegas National Conservation Area 2011 Update, at the 2011 CAMNet Rendezvous, unpublished manuscript). As they learn which treatments are most effective under which circumstances, they will determine the nature, timing, and location of management actions to reduce encroachment of invasive species.

Scientists and researchers based at universities and nongovernmental organizations and resource users may bring valuable monitoring and evaluation capabilities. For example, at LCNCA, the federal land manager partnered with a nongovernmental organization with science expertise to develop a monitoring plan that is targeted at collecting data needed to determine whether management actions are achieving management objectives (U.S. Department of the Interior 2003; K. Simms, G. Bodner, I. Tomlinson, and J. Williamson, 2010, Presentation on Collaboration and Adaptive Management at Las Cienegas National Conservation Area, at the 2010 CAMNet Rendezvous, unpublished manuscript). 
Stakeholder ideas and input can be collected in a variety of ways, including through in-person or telephone interviews, focus groups, informal conversations, meetings, and surveys. The purpose of gathering this input at key junctures in the adaptive management cycle is manifold and encompasses the following benefits:

- inform interested parties about the proposed adaptive management project or program;

- develop an understanding of the diversity of views about how the social-ecological system works;

- identify interests, issues of concern, management questions, and scientific hypotheses held by key stakeholders;

- identify management options to test, and expertise on monitoring design and project implementation; and,

- draw on diverse expertise and disciplines to interpret monitoring results and determine the most effective way to adjust management to achieve goals.

\section{Share data and information with stakeholders}

Providing a central location for resource and program data can create efficiencies for data-sharing, increase understanding of the complexities of an issue among diverse stakeholders, facilitate evaluation of monitoring results, and support informed decision making. These forums can be in-person, such as the stakeholder meetings convened annually by BLM for the LCNCA, or virtual, such as the Klamath Basin Decision Support System (http://www.klamathdss.org/index.php), an online forum designed to share resource data from government, nongovernmental organizations, and private sector firms with the public. Often a combination of both inperson and online forums works well.

\section{Identify in advance triggers or points in the process when monitoring results and new information will be evaluated to enable changes in management if warranted}

Schultz and Nie define a trigger as "pre-identified ... commitments in an adaptive management framework. Put simply, a trigger specifies what actions will be taken by an agency if monitoring information shows $\mathrm{x}$ or $\mathrm{y}$. In other words, some predetermined decisions, or more general courses of action, are built into the adaptive framework from the beginning of the process (i.e., if this, then what)" (Schultz and Nie 2012:444).

They note how organizations sometimes focus on the flexibility afforded by adaptive management, but fall short when it comes to making adjustments if monitoring results indicate the current management actions are not achieving the desired outcomes on the landscape. This lack of accountability often results in a loss of trust by affected stakeholders. Deciding in advance with stakeholder input what triggers and decisions will guide changes in management or operations ensures accountability and can lead to support for an adaptive management approach.

The Adaptive Management Team for CERP provides an example of how this can be done. They are developing Management Options Matrices for CERP Projects. These tables outline interim and full restoration targets, triggers for management action, and adjustments that can be made if project goals are not met. For example, the Draft Caloosahatchee Management Options Matrix identifies an interim target of mean monthly flow of $450-2800$ cubic feet per second (cfs) at varying percentages (for example, $74.5 \%$ of flows should be between $450-800 \mathrm{cfs}$ ). Not meeting this flow target would cause management to review the data and consider alternative management approaches for achieving the desired performance. The matrix outlines three options that managers can consider if the initial operating regime does not achieve its target.

\section{Design decision-making structures to incorporate and act on new information}

In 2011, Allen and Gunderson identified "action procrastination" and failure to use learning to modify policy and management as two of nine pathologies in design and implementation of adaptive management. These challenges can be mitigated by designing decision-making structures to take into account multiple points of view and act on scientific and other information gained through the collaborative adaptive management process.

Parties in an adaptive management program should outline agreed upon decision-making structures and approaches early in the process so that when new information becomes available, scientists know who they should provide information to and in what format, and those responsible for management have a process for consulting partners, making decisions, and acting on information learned from the adaptive management process. The Platte River Recovery Implementation Program has created a structure to support these steps in the adaptive management process. Through a negotiated agreement, the Program established a Governance Committee comprised of affected stakeholders, including representatives from two federal agencies, three states, water users, and two environmental groups. This Governance Committee makes decisions by consensus regarding the program's direction and implementation (J. Kenny and C. Smith, Platte River Recovery Implementation Program Presentation at 2009 CAMNet Rendezvous, unpublished manuscript). Program scientists analyze monitoring and research data and prepare a synthesis report to enable the Governance Committee to assess species and ecosystem response to program actions and determine if adjustments are needed to achieve program goals (Executive Summary prepared by Executive Director's Office of the Platte River 
Table 1. Mechanisms for multistakeholder collaboration and examples of adaptive management programs using each structure.

\begin{tabular}{ll}
\hline \hline Mechanism & Example \\
\hline Federal Advisory Committee & Glen Canyon Dam Adaptive Management Program \\
Stakeholder group convened by a nonfederal entity & Sonoita Valley Partnership - Las Cienegas National Conservation Area \\
Body established by legislation/agreement & Platte River Recovery Implementation Program \\
Federal Advisory Committee Act-exempt body & South Florida Ecosystem Restoration Task Force \\
\hline
\end{tabular}

Recovery Implementation Program, unpublished manuscript). Although the Platte River Recovery Implementation Program has yet to complete a full feedback loop, Governance Committee members are well positioned to act on new information as it becomes available because the Committee and its mode of decision making were established at the outset of the program and there is an explicit process in place for synthesizing scientific information and presenting it to policy makers.

\section{STRUCTURES FOR MULTISTAKEHOLDER COLLABORATION IN ADAPTIVE MANAGEMENT}

Parties should design collaborative processes to fit their specific circumstances and needs. When contemplating how to design decision-making structures to incorporate new information, adaptive management practitioners can benefit by observing structures that have been successfully used by other adaptive management programs to collaborate with affected stakeholders and use science to inform management. I review four mechanisms for multistakeholder collaboration that have been used by medium- to large-scale adaptive management programs in the U.S. and identify factors to consider when choosing among them or creating a new structure. These include: establishing a Federal Advisory Committee, forming a multistakeholder body convened by a nonfederal entity, creating a body through legislation or cooperative agreement, and seeking an exemption from FACA.

Adaptive management programs in the U.S. that are conducted in part or entirely on public lands and involve one or more federal agencies must consider the provisions of the Federal Advisory Committee Act (FACA). This law requires that federal agencies seeking collective advice or recommendations from individuals or organizations outside government form advisory committees that are diverse and balanced in their makeup and operate in an open and transparent manner (U.S. Senate 1972). Programs that do not involve federal agencies are not bound by the FACA; however, certain states have requirements that may influence how collaboration can be conducted on government projects within their jurisdiction. Table 1 presents four options for multistakeholder collaboration and an example of an adaptive management program that uses each one.

\section{Federal advisory committee}

The FACA lays out clear, established guidelines for getting consensus advice from a diverse array of stakeholders. This mechanism has the potential for delivering consensus recommendations, though members of a federal advisory committee may also report divergent opinions. Formation of a federal advisory committee requires approval by an agency head or administrator. The experience of the Glen Canyon Dam Adaptive Management Program suggests that the requirement for approval by high-level officials and vesting of the final decisions in the federal agency can afford a level of durability to the recommendations of the committee and decisions made by the agency, particularly when a decision is questioned in litigation (D. Kubly, personal communication).

Administrative resources are required to create a charter, participate in required training, and adhere to FACA charter guidelines. Once a committee is established, these resources are typically provided and used to support member involvement, for example through reimbursement of travel expenses associated with attending meetings. Because of the public nature of a federal advisory committee and the requirement for a diverse and balanced membership, the convening federal agency will very often follow the consensus advice of a federal advisory committee.

It is important to note that the committee's agreements are recommendations to the federal agency that chartered it, and final decisions are made by that agency. This, coupled with the extensive federal control of advisory committees operated under FACA may be problematic when an adaptive management program is addressing private lands in addition to public lands, or when other key partners would like to share leadership or make decisions jointly (Lynch 1996).

\section{Body convened by a nonfederal entity}

A group established by a nonfederal entity can convene a collaborative process that involves both government and other stakeholders. The courts have not found this type of group to be subject to FACA if the group does not provide consensus advice to an agency on federal policy (General Services Administration 2013) and if the nonfederal entity(ies) set the agenda, run the meetings, and receive funding from multiple sources (Lynch 1996). In the vicinity of the LCNCA, a group of citizens organized the Sonoita Valley Partnership (SVPP). 
The SVPP is a voluntary association of agencies, nongovernmental organizations, private sector interests, and individuals who work to achieve community oriented resolutions to local and national issues affecting public lands within the Sonoita Valley. This model demonstrates that involving stakeholders in the evaluation of monitoring results can facilitate adjustments in management when necessary. Because permittees are engaged from the beginning of the adaptive management process and are aware of monitoring efforts, they are willing and able to identify alternative grazing options in advance if monitoring results indicate a need to reduce the number of cattle on a particular permit (K. Simms, G. Bodner, I. Tomlinson, and J. Williamson 2010, Presentation on Collaboration and Adaptive Management at Las Cienegas National Conservation Area, at the 2010 CAMNet Rendezvous, unpublished manuscript).

This type of structure offers an opportunity of flexibility to tailor process and structure to meet the needs of specific circumstances. The administrative burden may be lower because a group organized and led by a nonfederal entity is not bound by FACA. One important consideration with this type of mechanism is that relevant agencies may decide whether or not to utilize the outcomes of the process.

\section{Body established by legislation or agreement}

A body established legislatively may or may not be subject to FACA, depending on the direction in the particular statute. Often, a group that has its genesis in legislation has some flexibility to structure itself in a way that facilitates collaboration and adaptive management. The Platte River Recovery Implementation Program's (PRRIP) Governance Committee was created through a cooperative agreement between the three Platte River Basin states and the Secretary of Interior in 1997. This multistakeholder decision-making body was formed to implement activities to support recovery of four threatened or endangered species. Chad Smith, Director of Natural Resources for the PRRIP, wrote in 2011 that the Program is an attempt to “... link science and management and engage a broad representation of entities in decision-making about species recovery and river management and policy" (Smith 2011:1415).

The Governance Committee comprises representatives from two federal agencies, three states, three water users, and two environmental entities. In contrast to groups operating under the FACA, this multistakeholder body is responsible for decision making and the consensus of the Governance Committee is implemented (G. Kenny and C. Smith, Platte River Recovery Implementation Program Presentation at 2009 CAMNet Rendezvous, unpublished manuscript). In this particular model, an independent firm that is not affiliated with any of the Governance Committee member institutions is responsible for day-to-day program operations. Having independent staff has proven particularly valuable in terms of maintaining confidence in data collection, analysis, and synthesis that decision makers use in the adaptive management process. This collaborative structure combined with independent program staff has preserved objectivity and the perception of it, built trust, and facilitated Program progress (Smith 2011). When considering this option, it is important to consider who will make decisions and how they will be made, how the program will be staffed, and the length of time required to pass legislation as well as to develop a customized structure and process.

\section{FACA-exempt body}

The FACA exempts certain bodies from its requirements, such as scientific bodies convened by the National Academy of Sciences and groups exempted from the act by statute (U.S. Senate 1997). The South Florida Ecosystem Restoration (SFER) Task Force (Task Force) was established through Section 528(f) of the Water Resources Development Act (WRDA) of 1996. This law exempted the SFER Task Force from FACA. The Task Force consists of 14 members from four sovereign entities. There are seven federal, two tribal, and five state and local government representatives on the Task Force. The SFER Task Force's Working Group addresses coordination of programmatic restoration issues and makes recommendations to the agencies responsible for implementing the Comprehensive Everglades Restoration Plan, the U.S. Army Corps of Engineers and South Florida Water Management District.

Section 4(f)(2) of the Endangered Species Act of 1973 provides another exemption from FACA: "The Secretary, in developing and implementing recovery plans, may procure the services of appropriate public and private agencies and institutions and other qualified persons. Recovery teams appointed pursuant to this subsection shall not be subject to the Federal Advisory Committee Act”' (U.S. Senate 1973).

A body formed through one of these provisions offers flexibility to tailor process and structure to meet the needs of specific circumstances. The administrative burden may be lower because of exemption from FACA; however, time is required to develop a customized structure and process if that is done. In addition, it is important to consider whether decision-making authority rests with the FACA-exempt body, or whether it is advisory to decision makers.

\section{CONCLUSION}

In conclusion, parties should consider a collaborative approach to scientific inquiry and learning when there are multiple jurisdictions, resource users, and viewpoints about the best way to manage a social-ecological system. Collaborative approaches can provide a process for stakeholders with relevant experience and expertise to contribute to adaptive management by identifying management goals and a range of management strategies, 
articulating divergent views about the best way to achieve management goals as hypotheses that can be tested, designing monitoring to inform key management questions, and interpreting data to inform decision making.

When designing collaborative approaches for adaptive management programs, it is important to provide forums for interaction between managers, scientists, and other stakeholders; invite input from affected stakeholders during each step of the adaptive management process; determine up front when monitoring will be evaluated and when management will be adapted if needed; and design decisionmaking bodies to incorporate and act on new information.

I review collaborative structures used by four adaptive management programs in the U.S. These include the federal advisory committee, body convened by a nonfederal entity, legislatively established body, and FACA-exempt groups. When creating a structure for collaboration to support adaptive management, parties should consider the jurisdictions responsible for management of the affected resource(s), the degree of collaboration and decision-making authority desired, who will make decisions, how decisions will be made, the amount of resources that will be required, and the length of time available to design and establish the group.

Responses to this article can be read online at: http://www.ecologyandsociety.org/issues/responses. $\mathrm{php} / 5709$

\section{Acknowledgments:}

I would like to acknowledge the participants in the Collaborative Adaptive Management Network (CAMNet) for sharing their experiences and knowledge to advance the practice of collaborative adaptive management. In particular, comments offered by Dennis Kubly and Chad Smith enhanced this article. Thanks also go to my colleagues at the Meridian Institute, Barbara Stinson and Robyn Paulekas, who reviewed and provided suggestions to improve drafts of this paper.

\section{LITERATURE CITED}

Allen, C. R., and L. H. Gunderson. 2011. Pathology and failure in the design and implementation of adaptive management. Nebraska Cooperative Fish and Wildlife Research Unit Staff Publications Paper 79, University of Nebraska-Lincoln, Lincoln, Nebraska, USA. [online] URL: http://digitalcommons. unl.edu/ncfwrustaff/79

Gates, C., F. Moore Lappé, J. Purdy, and B. Chafin Rash. 1991. NCR dialogue. Collaborative problem solving. National Civic Review 80(2):105-112. http://dx.doi.org/10.1002/ncr.4100800203
General Services Administration. 2013. When is the Federal Advisory Committee (FACA) applicable? General Services Administration, Washington, D.C., USA. [online] URL: http://www.gsa.gov/portal/content/100794

Holling, C. S., editor. 1978. Adaptive environmental assessment and management. Blackburn Press, Caldwell, New Jersey, USA.

Lynch, S. 1996. The Federal Advisory Committee Act: an obstacle to ecosystem management by federal agencies? Washington Law Review 71:431.

Nyberg, B. 1999. An introductory guide to adaptive management for project leaders and participants. B.C. Forest Service, Victoria, British Columbia, Canada.

Olsson P., C. Folke, and F. Berkes. 2004a. Adaptive comanagement for building resilience in social-ecological systems. Environmental Management. 34(1):75-90. http://dx. doi.org/10.1007/s00267-003-0101-7

Olsson, P., C. Folke, and T. Hahn. 2004b. Social-ecological transformation for ecosystem management: the development of adaptive co-management of a wetland landscape in southern Sweden. Ecology and Society 9(4): 2. [online] URL: http:// www.ecologyandsociety.org/vol9/iss4/art2/

Schultz, C., and M. Nie. 2012. Decision-making triggers, adaptive management, and natural resources law and planning. Natural Resources Journal 52:443-521. [online] URL: http:// lawlibrary.unm.edu/nrj/52/2/NMN207.pdf

Smith, C. B. 2011. Adaptive management on the central Platte River - science, engineering, and decision analysis to assist in the recovery of four species. Journal of Environmental Management 92:1414-1419. http://dx.doi.org/10.1016/j. jenvman.2010.10.013

Stankey, G. H., B. T. Bormann, C. Ryan, B. Shindler, V. Sturtevant, R. N. Clark, and C. Philpot. 2003. Adaptive management and the Northwest Forest Plan: rhetoric and reality. Journal of Forestry 101(1):40-46. [online] URL: http://www.fs.fed.us/pnw/pubs/journals/pnw_2003_stankey001. $\underline{\text { pdf }}$

Susskind, L., A. E. Camacho, and T. Schenk. 2012. A critical assessment of collaborative adaptive management in practice. Journal of Applied Ecology 49:47-51. http://dx.doi. org/10.1111/j.1365-2664.2011.02070.x

U.S. Department of the Interior, Bureau of Land Management, Arizona State Office, Tucson Field Office. 2003. Approved Las Cienegas resource management plan and record of decision. BLM/AZ/PL-03-010. U.S. Department of the Interior, Bureau of Land Management, Tucson Field Office, Arizona, USA. [online] URL: http://azmemory.azlibrary.gov/ cdm/singleitem/collection/feddocs/id/231/rec/2 
U.S. Fish and Wildlife Service Center. 2012. Adaptive harvest management. U.S. Fish and Wildlife Service, Washington, D. C., USA. [online] URL: http://www.fws.gov/migratorybirds/ CurrentBirdIssues/Management/AHM/AHM-intro.htm

U.S. Senate. 1972. Federal Advisory Committee Act. U.S. Senate, Washington, D.C., USA.

U.S. Senate. 1973. Endangered Species Act. U.S. Senate, Washington, D.C., USA. [online] URL: http://epw.senate. gov/esa73.pdf

U.S. Senate. 1997. The Federal Advisory Committee Act with Amendments and Annotations. U.S. Senate, Washington, D. C., USA. [online] URL: http://www.gsa.gov/portal/ content/100916

Walters, C. 1997. Challenges in adaptive management of riparian and coastal ecosystems. Conservation Ecology 1(2): 1. [online] URL: http://www.consecol.org/vol1/iss2/art1/

Windle, R., and S. Warren. 2013. Collaborative problem solving: steps in the process. Center for Appropriate Dispute Resolution in Special Education (CADRE), Eugene, Oregon, USA. [online] URL: http://www.directionservice.org/cadre/ section5.cfm\#

Woodrow, P., and S. Ghais. 1998. Effective collaborative processes on sustainable development and environmental policy: the Boulder principles. Collaborative Decision Resources, Boulder, Colorado, USA. [online] URL: http:// www.cgli.org/positions/IPPDbig.pdf 